\title{
Coming full circle: The Gender and Leadership Research Interest Group
}

2019 saw the Gender and Leadership Research Interest Group (G\&L RIG) come full circle. The international Women Leading Education across Continents conference, hosted in the UK, on behalf of the RIG, at the University of Nottingham, and the subsequent symposium composed of world-leading scholars at the BELMAS annual conference in Hinckley were the culmination of the RIG's evolution over the years.

This report aims to provide BELMAS members with an account of the G\&L RIG's activities in the last two years. First, we provide some context.

\section{Women Leading Education across Continents}

The field of women and gender in educational leadership, management and administration has developed, over three decades, from a focus on women's underrepresentation in educational leadership (still relevant), scholarship in women's leadership, to transforming leadership theory about the processes and purpose of that leadership.

The network Women Leading Education across Continents began in Rome in 2007 with founding members also members of BELMAS. Biennial conferences followed in Augsburg, Germany (2009), Volos, Greece (2011), Apam, Ghana (2013), Hamilton, New Zealand (2015), Rio de Janeiro, Brazil (2017) and Nottingham, UK (2019).

In 2011, the UK based delegates agreed to convene a UK based group. BELMAS supported that aim and in 2012 the G\&L RIG was launched.

\section{Intersectionality}

At the launch, Dr Marianne Coleman identified a need for further research on women in leadership using an intersectional lens. That chimed with the scholarship of founding coconveners whose work was already committed to recognising, further exploring and explaining the way gender and educational leadership identities intersect with race, religion and other facets. The G\&L RIG remains committed to surfacing women's opportunities and marginalisation in leadership across educational phases through an intersectional lens.

\section{Events}

Events have included meetings across England. The Leicester conference, hosted by Drs Joan Woodhouse and Saeeda Shah, led to a special issue of Management in Education themed 'Gender in educational leadership: Where are we in research?' co-edited by RIG convenors Victoria Showunmi, Pontso Moorosi, Joan Woodhouse, Saeeda Shah and Kay Fuller (2017).

\section{8}

The 2018 event took place at the University of Warwick. The host, Dr Pontso Moorosi, explained the significance of the G\&L RIG event, the RIG and its focus. Unlike previous events, usually attended by regular members of the RIG, the attendees at this event were mostly postgraduate students at Warwick, new to the RIG and BELMAS. At least three new members joined the Society, confirming the significance of bringing events closer to different communities. 
Keynote speakers were Dr Justine Mercer (Warwick), Professor Jaswinder Dhillon (University of Worcester) and Dr Victoria Showunmi (UCL).

Dr Mercer's address, titled '(Mis)recognition, reproduction and resistance within the UK (full) professoriate', analysed the extent to which the gendered symbolic order of the UK professoriate is recognised, misrecognised, reproduced and/or resisted. Her presentation focused on a large UK study that involved both male and female professors. The project was part-funded by BELMAS. Dr Mercer ended by reflecting on the challenges of publication, which was helpful for our student and early career audience.

Professor Dhillon's engaging keynote address, 'Women's perceptions of outstanding leadership: fitting in or challenging expectations?' was also based on a BELMAS funded project. This presentation involved attendees sorting statements about characteristics of outstanding leadership on a Q-sort grid. Deciding, individually or in groups, which statements they most agree or disagree with, prompted participants to prioritise leadership characteristics and reflect on them. Many attendees learned for the first time about Qmethodology as applied in leadership studies.

Dr Showunmi ended with a keynote address on 'Gender Identity and Leadership' and particularly engaged attendees with her signature question, "Who are you?", before her very thought-provoking address on an intersectional reflection on identity and leadership.

\section{9}

The G\&L RIG has been planning the international conference of Women Leading Education across Continents for some time. The event took place at the University of Nottingham, hosted by Dr Kay Fuller on behalf of the G\&L RIG. Approximately fifty papers addressed the theme 'Ways of seeing women's leadership in education: stories, images, metaphors, methods and theories'. The conference publication, co-edited by the G\&L co-conveners, a Research Topic for Frontiers in Education, is in production.

The conference was attended by 90 delegates from countries across all six continents. Donations and scholarships, from a range of organisations, provided full scholarships for sixteen delegates from developing countries. The BELMAS G\&L RIG provided day delegate scholarships for eighteen international and UK based members. A BELMAS project designed to 'Join up Networks in Education for Women' led by Dr Kay Fuller, Dr Joanne Cliffe and Vivienne Porritt further supported twenty day delegates from the East and West Midlands.

As is traditional, the cultural day took 39 delegates to Wollaton Hall to explore history (architecture and global artefacts), legend (Robin Hood), sport (archery) and drama. In an attempt to decolonise the conference, delegates performed a scene from Shakespeare's Antony and Cleopatra in an exploration of African women's leadership.

Several delegates moved on to the BELMAS annual conference at Hinckley where the 'Women Leading Education Across Continents - Educational Leadership for Social Change Symposium', chaired by Drs Pontso Moorosi and Victoria Showunmi, included presentations by Professors Margaret Grogan and Charol Shakeshaft and Drs Elizabeth Reilly and Saeeda Shah. This symposium explored insights into the means by which women in educational leadership across the world overcome persistent challenges and strive, through their leadership, to achieve a more socially just society. Presenters addressed questions exploring 
barriers that women leaders seek to overcome for themselves and others. The symposium aimed to broaden BELMAS international community building by bringing together these international networks of scholars.

\section{Future plans}

G\&L RIG members aim to continue their collaboration in comparative research projects (and share their research through presentations and publications as described above. The coconveners are currently planning to consult BELMAS members about its future activities.

Dr Kay Fuller

Dr Pontso Moorosi

Dr Saeeda Shah

Dr Victoria Showunmi 